\title{
«LIBRAOS DE ULTRAMAR». BENTHAM FRENTE A ESPAÑA Y SUS COLONIAS ${ }^{1}$
}

\author{
CARLOS RODRIGUEZ BRAUN \\ Universidad Complutense
}

No tengo el honor de ser español.

Tengo el deshonor de ser inglés.

Jeremy BENTHAM

\section{INTRODUCCION}

Sabido es que el filósofo inglés Jeremy Bentham (1748-1832), a quien se asocia en economía con la teoría de la utilidad, mantuvo intensas relaciones, en diversos momentos de su vida, con España, los españoles y los hispanoamericanos. El presente artículo analiza con detalle la obra de Bentham «Libraos de Ultramar», un manuscrito que ha permanecido inédito hasta hoy, y es muy poco conocido ${ }^{2}$. Rid Yourselves of Ultramaria, tal su título original, fue redactado entre 1820 y 1822 y, aunque su mensaje manifiesto es insistir a los españoles sobre la conveniencia de la emancipación de sus colonias, tiene un objetivo último bastante diferente; el septuagenario Bentham pretendía llamar la atención sobre ciertos peligros que se cernían sobre el régimen liberal en España, derivados especialmente de las deficiencias que, según el inglés, aquejaban a la Constitución de Cádiz de 1812.

El artículo está dividido en dos partes: en la primera se analiza la historia y el mensaje de «Libraos de Ultramar», y en la segunda se da cuenta del contenido de la obra.

\footnotetext{
' Este artículo se basa en el capítulo VI y el apénilice de mi tesis doctoral; cfr. C. Rodríguez Braun (1984). Aprovecho para agradecer los comentarios de los miembros del Tribunal Gonzalo Anes y Jesús González; de su presidente, Luis Angel Rojo, y la gran avuda prestada por mi tutor de tesis, Pedro Schwartz.

: En castellano, la única referencia que conozco sobre esta obra de Bentham es P. Schwartz (1983). En otros idfiomas puede citarse a $M$. Williford (1980), autora que untra con alguna amplitud en la exposición de «Libraos». Una edición provisional de este trabajo de Bentham ha sido incluida como apéndice en mi tesis doctoral.
} 


\section{HISTORIA Y MENSAJE DE «LIBRAOS DE ULTRAMAR»}

La influencia de Bentham en España — donde llegó a ser, en expresión de Halévy, «una especie de semidiós» ${ }^{3}$ - fue muy considerable, tal como lo han puesto de manifiesto los especialistas en diversas oportunidades y lo revelan tanto las obras que Bentham escribió dirigidas a (o suscitadas por) España ${ }^{4}$ como la edición provisional de su Correspondencia Ibérica ${ }^{5}$. La extensión del benthamismo en Portugal e Iberoamérica fue también significativa ${ }^{6}$.

Los primeros benthamistas españoles tomaron contacto con las ideas del maestro a través de sus obras editadas en Francia, que penetraron en la Península con Napoleón. Fue un consuelo irónico para Bentham: los militares herederos de la Revolución ayudaron a pasar la doctrina del filósofo a España y.Portugal y, desde allí, a América ${ }^{7}$.

Dos obras benthamianas dirigidas a Francia tuvieron facetas españolas, aunque más prometedoras que efectivas. En primer lugar, la Táctica de las Asambleas Políticas, que escribió en 1789 para los Estados Generales galos. En 1810, bajo la inspiración de José Blanco White, lord Holland, el ex vicepresidente norteamericano Aaron Burr y E. Dumont, decide Bentham publicar la Táctica en español, como manual de orden parlamentario; el libro apareció por fin en francés en $1816^{\circ}$. En segundo lugar, Bentham pensó adaptar su panfleto antiimperialista Emancipate your colonies!, de 1793, para uso de españoles e iberoamericanos. Este intento tendría menos suerte que el anterior, pero su resultado final nunca llegaría a hacerse público ${ }^{9}$

Empieza Bentham a trabajar en el manuscrito anticolonialista para España a mediados de 1820 , y lo titula provisionalmente «Emancipación Española», Emancipation Spanish. A los pocos meses, sin haber avanzado mucho, lo cambia de nombre a "Libraos de Ultramar", Rid Yourselves of Ultramaria, un ensayo con forma epistolar.

Hay varios testimonios de esta obra en la correspondencia de Bentham; éste había participado del interés que suscitaban entonces las colonias espa-

${ }^{3}$ E. Halévy (1901-1904), vol. II, p. 276.

- Algunas de las cuales fueron publicadas en español en aquella época, como Consejos que dirige á las Cortes y al pueblo español Jeremias Bentham, en 1820, y Cartas de Jeremias Bentham, al Señor Conde de Toreno, sobre el Proyecto de Código Penal, en 1822, ambas traducidas por el activo José Joaquín de Mora.

3 J. Bentham (1979). El análisis más completo del impacto de Bentham en España es P. Schwartz (1976).

- Se ha sostenido que la influencia de Bentham fue más profunda en Iberoamérica que en la propia España; cfr. G. W. Keeton y G. Scharzenberger (1970), p. 216, y O. C. Stoetzer (1966), vol. II, pp. 115 y ss.

J. H. Burns (1966), p. 114.

- Con el título Táctica de las Asambleas Legislativas.

${ }^{9}$ P. Schwartz y C. Rodríguez Braun (1983), pp. 59-60. 
ñolas ${ }^{10}$ y tuvo bastante relación con importantes figuras iberoamericanas, entre las que se contaba Bernardino Rivadavia, un argentino que iba a ser presidente de su país y que había venido a Europa en busca de un rey para el Río de la Plata. Antes de comenzar «Emancipación Española», en la primavera de 1820 , Bentham escribe a Rivadavia y le envía una copia de su Emancipate your colonies!, comentándole que siempre ha sido hostil con respecto a los imperios:

... todas las colonias y dependencias lejanas son, sin excepción, esencialmente perjudiciales ... para la gran mayoría de los pueblos de ambas partes ${ }^{11}$.

Apunta Bentham al argentino que lo único que habría que agregar al panfleto es alguna reflexión sobre la «influencia corruptiva» que el patronazgo sobre las colonias ejerce en los representantes del pueblo en la metrópoli. Piensa que no se encuentra en condiciones de realizar la aplicación práctica de la obra al caso español e invita a Rivadavia a que lleve adelante la tarea, traduciendo Emancipate al español. A la postre, empero, será el propio Bentham el que se encargue del trabajo.

Hay una mención al «folleto sobre la emancipación» en dos cartas que escribe a José Joaquín de Mora, en septiembre de 1820; Mora había propuesto traducir el capitulo sobre las colonias de Teoría de las Penas y las Recompensas ${ }^{12}$, capítulo que Dumont había compuesto con materiales del «Instituto de Economía Política» y de Emancipate your colonies! En cartas a Mora de noviembre del mismo año, el folleto es mencionado con su nuevo y definitivo nombre: Rid Yourselves of Ultramaria ${ }^{13}$. El 24 de diciembre, Bentham escribe a otro iberoamericano eminente, Simón Bolívar:

Desde hace algún tiempo he estado trabajando, a más no poder, al servicio conjunto de Ud. y su - hasta recientemente- inhumano enemigo. Digo al servicio conjunto pues el título de mi obra es «Libraos de Ultramar». Le falta poco para estar completa ${ }^{14}$.

${ }^{10}$ Véanse, por ejemplo, J. Alberich (1980) y V. Llorens (1979).

$"$ J. Bentham (1979), vol. I, p. 138. Las colonias, sin embargo, son beneficiosas para los gobernantes, por lo que éstos se resisten a abandonarlas. Escribe Bentham a E. Blaquière, en junio de 1820: «Actualmente estoy trabajando intensamente en un proyecto casi sin esperanzas: convencer a los que mandan en España, quienesquiera que sean, para que emancipen a toda América Española.» Ibidem, p. 145.

${ }_{12}$ Ibidem, pp. 246, 256 y 266.

${ }^{13}$ Ibidem, pp. 296, 309 y 315.

is Ibidem, p. 398. 
Sin embargo, «Libraos» no estaba casi completo. Bentham trabajó en el ensayo hasta agosto de 1821 y, después, en marzo y abril de 1822 . La obra quedó inconclusa y no fue publicada, por fin, en idioma alguno.

Una sección de «Libraos de Ultramar», no obstante, iba a ser publicada en vida de Bentham, pero no apareció como parte de dicha obra, sino como trabajo independiente. En 1821, John Bowring, el amigo y albacea de Bentham, iba a publicar las Observaciones sobre el sistema comercial restrictivo y probibitivo ${ }^{15}$, en donde Bentham criticaba un decreto proteccionista de las Cortes españolas. Este texto, que debía haber sido un apéndice de «Libraos», fue así lo único de la misma que vio la luz finalmente. Tiene mucho de economía, y es bastante interesante, puesto que Bentham expone sutiles argumentos contra la protección --incluso la que ampara a las industrias nacientes o a lo que modernamente se llamaría reconversión industrial ${ }^{16}$ - y en favor del libre comercio. Pero las Observaciones no contienen reflexiones sobre la cuestión colonial ni sobre España: ello quizá explique por qué Bentham optó por autorizar su publicación por separado ${ }^{17}$.

Aún más que en otras circunstancias, en «Libraos» piensa Bentham en términos jurídicos y políticos, en la formación de una nueva burocracia - transparente y controlable, pero burocracia al fin- que prefigura el moderno Estado de bienestar ${ }^{18}$. España y sus colonias son uno de los puntos de partida del análisis que Bentham iba a culminar en su Código Constitucional ${ }^{19}$.

En términos económicos, la baja rentabilidad de las colonias está fuera de toda cuestión, y así lo aclara Bentham en una carta a Mora en la que le comenta el nuevo título de su obra:

El título propuesto es Rid Yourselves of Ultramaria. Cuando en inglés empleamos la palabra Rid queremos decir que aquello de lo que hablamos es una carga... ${ }^{20}$.

15 Observations on the Restrictive and Probibitory Commercial System; obra no traducida al español, fue incluida por W. Stark en el vol. III de J. Bentham (1952), sin vincularla con «Libraos». Cfr., también, C. M. Atkinson (1969), p. 195.

${ }^{16}$ C. Rodríguez Braun (1984), pp. 568 y ss.

17 En una carta que escribió, pero no envió, a Chile en 1821 , se refiere Bentham a ambas obras, Rid Yourselves y las Observations, sin establecer relación entre ellas. Esta carta, junto con la cual pensó Bentham enviar los títulos de las cartas que componían "Libraos» y un ejemplar de las Observations, ha sido traducida al español y publicada en Chile; cfr. M. Estelle (1977). Al parecer, el destinatario de la carta iba a ser Bernardo O'Higgins.

${ }_{18}^{18}$ L. J. Hume (1970 y 1981) y D. Roberts (1959).

${ }^{14}$ L. J. Hume (1981), p. 237; C. W. Everett (1966). Los aspectos económicos son poco importantes en este análisis; cfr. L. J. Hume (1967), p. 362.

so J. Bentham (1979), vol. I, p. 315. 
En cuanto a los fundamentos teóricos, es de destacar la ausencia del principio de no more trade than capital: la actividad económica está limitada por el capital existente ${ }^{21}$. Este principio, que Bentham toma de Adam Smith, había sido muy usado en sus primeras obras económicas anticoloniales, en el último cuarto del siglo xvin, Cierto es que Bentham argumenta a veces en "Libraos" que la emancipación colonial traerá la prosperidad:

Veréis al dinero fluir hacia vosotros en ríos infinitos... ${ }^{22}$;

pero el mensaje económico que desea transmitir a los españoles es que las colonias cuestan mucho y no proporcionan beneficio alguno a la «mayoría oprimida». Muchas páginas consume el filósofo para demostrar que no hay forma de obtener más impuestos de Ultramaria, expresión que inventa a partir del «Ultramar» que lee en la Constitución española de 1812. Bentham sostendrá que lo único que podrá esperar el pueblo de España de sus dominios americanos es un aumento de los impuestos... pagados en la madre patria.

La Constitución de Cádiz: tal el objetivo central de «Libraos de Ultramar». Los comentarios económicos resultan insignificantes junto al tema constitucional: no hay prácticamente carta que no toque este asunto, y en muchas de ellas la Constitución liberal es el único objeto de análisis.

En la cuestión colonial, por tanto, Bentham gira hacia la legislación, campo en el que tenía puestas todas sus —en verdad excesivas ${ }^{23}$ - esperanzas. Más que por los problemas económicos relativos al Imperio, Bentham está preocupado por algo de lo que no tenía conciencia cuando escribió Emancipate your colonies!, en 1793 :

el interés siniestro, la auténtica raíz del desgobierno ${ }^{24}$.

Beritham abundará en la cuestión de los sinister interests en varias de las cartas que componen «Libraos», en especial en segunda carta de la primera parte, que incluye un análisis exhaustivo de las clases y grupos sociales afectados por la emancipación de Ultramar. Quizá sean estas páginas las más interesantes desde la óptica económica, puesto que remiten al moderno enfoque de la decisión pública ${ }^{25}$.

Todo ello plantea sugerentes problemas políticos — por ejemplo, ¿por qué la «mayoría oprimida» no se rebela?-, pero tiene poco que ver con la cuestión colonial. La minoría opresora seguiría oprimiendo aunque no hubiese

${ }^{21}$ En contra de lo que se sostiene en P. Schwartz (1983), p. 150.

"C. Rodríguez Braun (1984), p. 501.

${ }^{3}$ R. A. Posner (1976), p. 601.

4 C. Rodríguez Braun (1984), p. 355.

". P. Schwartz (1983), p. 153. 
Imperio. Parece, en efecto, que las colonias españolas son utilizadas por Bentham como trampolín para llegar a lo que verdaderamente le inquieta con respecto a España: la estabilidad del régimen liberal, que ya una vez había sido derrotado. Esto permite resolver la siguiente cuestión: ¿por qué se ocupa Bentham de las colonias españolas cuando parecía que muchas de ellas se estaban independizando? ${ }^{26}$. La respuesta podría ser: porque no estaba escribiendo sobre colonias, sino sobre la situación de España. Al mismo tiempo, se estaba carteando con iberoamericanos, ofreciéndose como legislador. En «Libraos" ofrece también sus servicios, y se declara candorosamente exento de toda corruptibilidad ${ }^{27}$. Las colonias podrían desaparecer, pero la Constitución de 1812 no, y Bentham veía en ella - la estudió minuciosamente- múltiples defectos. La mayor parte de los males, desde lo breve del período de sesiones de las Cortes hasta la dificultad para la reforma del texto constitucional y el incontrolable poder de patronazgo del rey, resultan independientes en gran medida de Ultramar: seguirían existiendo aunque las colonias se desvaneciesen.

Parece como si Bentham hubiese empezado por la cuestión colonial y, al percibir la importancia del problema constitucional, hubiese desviado su atención hacia éste, del que había mucho que decir. Por eso repite, aquí como en otros trabajos suyos, que la obra está «casi» completa. En el verano de 1820 escribe a un discípulo suyo que al libro sobre la emancipación americana «le falta poco para estar terminado, pero sin duda le falta algo». Ha descubierto Bentham que las colonias y la Constitución son incompatibles:

Ello me ha conducido a la necesidad de revelar los defectos que tiene la Constitución, defectos tan graves que, de no ser remediados, todo acabará en una ruina completa, o el despotismo tomará el lugar de la libertad ${ }^{28}$.

Bentham envió informes sobre Rid Yourselves of Ultramaria y partes de la obra a España - por ejemplo, a Toribio Núñez y a Mora, que inició su traducción ${ }^{29}$-, a México ${ }^{30}$ y a Portugal ${ }^{31}$. Pero fue perdiendo su optimismo con respecto a España; en mayo de 1822 escribe a un amigo, que combatía junto a Bolívar:

\footnotetext{
${ }^{26}$ M. Williford (1980), p. 45; cfr., también, J. Bentham (1979), vol. I, p. 154.

${ }^{27}$ C. Rodríguez Braun (1984), pp. $472-476$.

26. Bentham (1979), vol. I, p. 182.

Ibidem, vol. II, pp. 695, 707, 727 y $861-862$.

${ }^{30}$ Ibidem, : 761 .

${ }^{31}$ Ibidem, pp. 706-709 y 719-720.
} 
En las mentes de los gobernantes españoles, incluso de la España regenerada, la imbecilidad es completamente infantil. Toda Ultramar: eso es lo que quieren tener y, para cuando Ud. reciba esta carta, más valdría decir reconquistar. Cuando hayan conquistado la luna y la hayan depositado en El Escorial, entonces será el tiempo de iniciar la reconquista de Ultramar ${ }^{32}$.

Un mes después admite, en cartas a los argentinos José de San Martín y Bernardino Rivadavia, que «Libraos de Ultramar» no está aún terminado ${ }^{33}$. $\mathrm{Y}$ un año después, en junio de 1823 , le dice a Bolívar que probablemente «Libraos» no se publique jamás ${ }^{34}$. España continuaba en posesión, al menos formal, de su Imperio. Pero lo que ya no tenía era el régimen liberal.

\section{CONTENIDO DE «LIBRAOS DE ULTRAMAR*}

«Libraos de Ultramar", con el subtítulo «Consejos que Jeremy Bentham da al pueblo de España, en una serie de cartas», no llegó a ser un libro. Tras iniciarla dos veces, Bentham abandonó la empresa en una situación tal que el trabajo no puede ser calificado más que de borrador. El University College de Londres efectuó una transcripción mecanográfica de los manuscritos, y sobre este material realicé una traducción española y edición provisional, incluida como apéndice en mi tesis doctoral. Pese a que, entonces, la edición definitiva de «Libraos» está aún pendiente, el trabajo realizado puede servir para dar cuenta de esta importante y virtualmente desconocida obra de un gran pensador y gran amigo de España.

«Libraos de Ultramar», cuya edición provisional ocupa unos 250 folios a doble espacio, está dividido en dos partes cuyos títulos son «Daño a España por las pretensiones expresadas en su nombre sobre las provincias ultramarinas españolas» y «Daño al Ultramar español por las pretensiones de dominio en nombre de España».

\section{Primera parte}

Los tres cuartos de «Libraos» que se conservan corresponden a su primera parte. Bentham proyectó escribir diecinueve cartas, pero sólo dejó material para once; más de la mitad de dicho material se concentra en las tres primeras.

La carta 1 presenta el plan de la obra, en el que Bentham adelanta su

\footnotetext{
${ }^{32}$ Ibidem, p. 727.

33 Ibidem, pp. 747 y 761 .

It Ibidem, p. 850.
} 
opinión sobre las colonias españolas: benefician tan sólo a la «minoría dirigente», ruling few, y perjudican a las mayorías sometidas, subject many, tanto en la Península como en Ultramar. Lo que conviene a los pueblos a ambos lados del Atlántico es, para Bentham, indudable: la separación ${ }^{35}$. Empieza aquí Bentham a destacar los problemas constitucionales de la colonización, verdadero leit motif de «Libraos»: la relación entre las colonias y la Constitución de Cádiz de 1812, que Riego había restablecido en 1821 .

En la extensa e importante carta 2, ya mencionada, «Distinciones Preliminares. Intereses Afectados", Bentham entra con muchísimo detalle en los diversos sectores y grupos sociales favorecidos por la preservación del status colonial. Su punto de partida es que el interés de la mayoría, el general, se enfrenta a intereses que le son adversos: los siniestros. La única forma de impedir que la minoría consume el «sacrificio siniestro» -el logro de su interés a expensas del de la mayoría - estriba en la democracia representativa, que garantiza que los representantes puedan ser removidos antes de que se corrompan - la vinculación estrecha entre colonias y corrupción, tradicional argumento antiimperialista, aparece en numerosas oportunidades en «Libraos»-. Ejemplo insigne de dicha democracia son los Estados Unidos, a los que Bentham cubre de elogios en varias ocasiones ${ }^{36}$. Pese a las excesivas ilusiones que se hacía Bentham con respecto a ese país, es de destacar en principio su idea de la gran capacidad que tiene la democracia para fomentar la felicidad de la mayoría.

Sin embargo, en su análisis de los conflictos de intereses, Bentham elude en general toda consideración al mutuo interés, y a los tratos o negocios voluntarios, lo que es una limitación de su enfoque: difícil resultaría argüir que la felicidad depende básicamente de la obediencia a una mayoría y no de acuerdos voluntarios. Por otro lado, parece que la teoría del Estado de Bentham es defectuosa, por muchos elementos de public choice que contenga: no sólo en un régimen democrático hay (plena) coincidencia entre los intereses de la mayoría gobernada y la minoría gobernante; se ha sostenido que la existencia de unidad de acción ha sido tan beneficiosa para la raza humana que ésta tiene genéticamente impreso el sentimiento de obediencia a la autoridad. $\mathrm{Y}$ un buen antídoto para el exceso de poder serían, precisamente, esos acuerdos voluntarios que Bentham olvida.

Pero los choques de intereses son, para Bentham, mucho más relevantes que los tratos voluntarios. El argumento central de esta carta es que las colonias, al requerir un incremento en los impuestos o un desvío del gasto público hacia el mantenimiento del Imperio ultramarino, podrían introducir una contradicción en el seno de la minoría dirigente, una cuña entre los ruling

39 C. Rodríguez Braun (1984), p. 364.

36 Ibidem, pp. 362, 403, 435, 453.454. 
few. Al resistirse a ver reducidos sus privilegios económicos, algunos miembros de dicha minoria se opondrán al mantenimiento de las colonias y se colocarán objetivamente junto al interés general, por más que actúen movidos exclusivamente por un sentimiento egoísta. Bentham aconseja:

Ahora es por tanto el momento de que todos los amigos del interés común se esfuercen para aprovechar al máximo el apoyo de estos aliados temporales ${ }^{37}$.

A partir de la carta 3, «Ultramar sometido: ningún beneficio», Bentham plantea la idea de que España no podrá mantener su Imperio y la Constitución de 1812 a la vez: ese Código conspira contra la preservación de Ultramar, especialmente por el principio de la igualdad de derechos entre todos los españoles, sea que habiten en la metrópoli o en las colonias. En esta carta y las dos siguientes ( «Bajo la Constitución: ningún beneficio» y «Sumisión de Ultramar: por qué es imposible») puede verse hasta qué punto cree Bentham que el marco jurídico-constitucional es todo en la vida de una comunidad. Será simplemente por la lectura de la Constitución que los criollos decidirán no pagar más impuestos... ${ }^{38}$.

Desde este punto puede verse que una buena proporción de «Libraos» nunca llegó a ser escrita: es el caso de las cartas $6,7,12,14,16-19$ de la primera parte y las $2-4,8,12$ y 13 de la segunda. Puede comprobarse también que varias de las epístolas que sí escribió Bentham están apenas esbozadas.

En la carta 8, "Influencia corruptiva: aumentada», arremete una vez más Bentham sobre la Constitución y pronostica un incremento en la corrupción, dado que el gobierno español es todavía «mixto», pues tiene elementos monárquicos y democráticos, y esa mixtura es para Bentham deletérea:

Las únicas formas de gobierno que, salvo accidentes, son capaces de preservar su existencia permanentemente son la monarquía pura y la democracia representativa pura: la monarquía, si es capaz de excluir las luces del progreso, y la democracia en virtud, precisamente, de dichas luces ${ }^{39}$.

Otra vez, Bentham no concibe que puedan existir mecanismos autocorrectores y equilibradores en la sociedad -ni en el hombre-. Por eso detesta los sistemas mixtos y no contempla la posibilidad de que tengan lugar coaliciones, tratos o contratos de beneficio general. Este beneficio sólo se alcanza,

\footnotetext{
37 Ibidem, p. 417.

Ibidem, pp. 424 y ss.

39 Ibidem, p. 466.
} 
según Bentham, cuando una parte hace coincidir el interés de otra exactamente con el suyo, cuando la mayoría sometida obliga a la minoría dirigente a ponerse totalmente a su servicio y condiciona el pago de emolumentos a una servidumbre total. Por eso ataca Bentham al sistema bicameral - no le preocupan los frenos y contrapesos- y aboga por una transparencia absoluta en la vida pública. Bentham no comprende los beneficios de la descentralización y se aferra a una noción de la democracia que equivale a una pirámide de soberanía responsable.

En las cartas 9, 10 y 11 ( «Malos diputados: inamovibles durante más tiempo», «Tiempo de las Cortes: desperdiciado» y «Despotismo secretamente establecido ) prosigue Bentham detallando los males que el Imperio añade a las ya deficientes instituciones metropolitanas, como la inmovilidad de los diputados o el escaso tiempo de sesiones de las Cortes, y concluye que la conservación de Ultramar requerirá la implantación allí de un régimen despótico, mucho más perjudicial que los mayores costes económicos, puesto que el despotismo de Ultramar contagiaría a la Península:

El gasto en dinero, no obstante, no es el más grave de los males.

Lo peor es el despotismo. Así, la Constitución, que pretendió suprimir el despotismo en ambos hemisferios, podría reestablecerlo en América y, por eso mismo, también en Europa ${ }^{*}$.

Tras la carta 13, «El abandono es rentable», donde Bentham recuerda que el comercio anglo-norteamericano no disminuyó con el nacimiento de los Estados Unidos, la última carta de esta primera parte que se conserva es la 15, «Mancha del tráfico de esclavos: borrada», donde es de destacar que Bentham establece una diferencia entre la trata de esclavos, que desaprueba, y la esclavitud misma, que se resiste a condenar taxativamente: la emancipación de todos los esclavos, en efecto, no garantiza ni su subsistencia ni la seguridad general; por ello, en el estricto utilitarismo de Bentham, dicha emancipación no puede proponerse irreflexivamente ${ }^{41}$.

\section{Segunda parte}

Para la segunda parte, Bentham alcanzó a redactar manuscritos - pero frecuentemente apenas esbozos - de siete de las trece cartas originalmente planeadas. En términos generales resulta significativo, a tenor de lo ya indicado sobre las preocupaciones del autor al escribir esta obra, el que Bentham base

"Ibidem, p. 495.

"Ibidem, p. 508. 
muchos de sus argumentos en los males que las colonias producen en la Península.

La carta 1, «Causas de la aversión de Ultramar», se abre con un exagerado diagnóstico sobre la calidad de la administración imperial española, y con una interesante pregunta política:

Ultramar se sometió a todos los males bajo el peor gobierno que jamás haya existido. Entonces, alguien podrá preguntar, ¿por qué no se someterá a un gobierno mejor? ${ }^{42}$.

En síntesis, su respuesta estriba en que el Antiguo Régimen era represivo, pero que las «luces» y la libertad presentes en la Constitución española animarán el sentimiento independentista, a partir de las restricciones impuestas a Ultramar, que, ahora sí, hará sentir su repulsa en la práctica. Bentham comenta dichas restricciones en el plano legislativo en la carta 5, «Nula legislación en Ultramar», y representativo-constitucional en las cartas 6 y 7, «Representación en las Cortes: inútil» y «Diputados de Ultramar: ninguno». En el aspecto constitucional, el título de la carta 9 expresa una de las grandes objeciones de Bentham al régimen liberal español: «La Constitución no es reformable».

El texto constitucional no podía ser cambiado antes de que hubiesen pasado ocho años desde su puesta en vigor. Bentham opina que es

un ejemplo memorable de hasta qué extremo la autosuficiencia y la ineptitud pueden devanarse en el corazón humano ${ }^{43}$.

Podría argumentarse aquí, contra Bentham, que no es necesariamente beneficioso el que no exista mayor dificultad para modificar leyes fundamentales. Como en oportunidades anteriores, Bentham no admite la noción de jerarquía de normas como método de autocontrol de los mandatarios. Para él, la ley es la manifestación de la voluntad del pueblo, que no puede obrar contra su propio interés, $y$, por consiguiente, no hay necesidad de limitaciones ni de diferencias de rango normativo. Este concepto. extremadamente positivista de la ley tira por la ventana lo que hay de bueno en el iusnaturalismo: la concepción de la ley como una barrera frente a los caprichos del soberano, porque es anterior a su voluntad.

Las últimas cartas que se han preservado de esta segunda parte son curiosas. La carta 10 lleva por título «Es mejor que Ultramar gobierne España», que en realidad no es una opinión de Bentham, sino una posibilidad: dado

42 Ibidem, p. 512.

43 Ibidem, p. 544. 
que la Constitución determina que el objetivo del gobierno debe ser la felicidad de la mayoría, una eventual superioridad demográfica de Ultramar obligaría a trasladar el ejercicio del poder al otro lado del Atlántico. La carta 11 también tiene un encabezamiento equívoco: «Es preferible conquistar la Berbería»; no se trata, en verdad, de un consejo de Bentham, sino de una comparación: el coste de una aventura colonial en el norte de Africa resultaría menor que el del mantenimiento del Imperio ultramarino *. En esta breve carta es destacable una noción de "pérdidas y ganancias» para la evaluación de proyectos - al estilo del moderno análisis de coste/beneficio- que exige comparación interpersonal de utilidades.

\section{RESUMEN Y CONCLUSIONES}

El anciano Jeremy Bentham, que se había convertido a partir de la primera década del siglo xix en el líder intelectual de los "radicales filosóficos», aconsejó a los españoles «Libraos de Ultramar», mensaje en el que la atención a la situación de la España del trienio liberal es mayor a la dispensada al - por otra parte tambaleante- Imperio. El manuscrito Rid Yourselves of Ultramaria, que ha permanecido inédito hasta la fecha, fue redactado por Bentham entre 1820 y 1822 . Aunque trata del Imperio español, parece claro que el objetivo de Bentham era más bien alertar a los españoles sobre las deficiencias de su sistema político en la metrópoli, determinado por el restablecimiento de la Constitución de 1812. Bentham abandona la obra a medio terminar en 1823, cuando España, aún en posesión formal de su Imperio, pierde su régimen liberal. El mensaje de Bentham es, sin duda, anticolonial, pero lo que sostiene es que las dependencias ultramarinas añaden perjuicios al ya de por sí defectuoso marco institucional español.

Si las colonias son mantenidas, afirma Bentham, ello sólo beneficiará a la «minoría dirigente» en contra de la «mayoría sometida», que, en ambos lados del Atlántico, se vería favorecida por una amistosa separación. En el estilo de la reciente teoría de la elección colectiva, Bentham diseca a las clases y grupos de presión de la sociedad española, y descubre que la preservación del Imperio puede llegar a atentar contra los intereses de algunos de estos grupos, por lo que la acción popular debería encaminarse a aprovechar políticamente estas contradicciones en el seno de las clases dominantes.

En estas cartas — «Libraos» tiene forma epistolar-, Bentham se ocupa

" Uno de los argumentos básicos es la lejanía de las colonias españolas -problema sobre el que ya había reflexionado Montesquieu a mediados del siglo anterior-. En $\& \mathrm{Li}$. braos de Ultramar», Bentham señala en varias oportunidades a los españoles que la dis. tancia que separa a sus colonias de la metrópoli está en la base de la inviabilidad de cualquier proyecto imperial de España en América. 
mucho más de los conflictos de intereses que de los acuerdos voluntarios a que las personas pueden arribar en beneficio mutuo. Con una visión extremadamente positivista de la ley, Bentham no admite mecanismos autocorrectores sociales, sino sólo la democracia plena, entendida ésta como una pirámide burocrática donde los gobernantes son permanentemente controlados (y destituidos) por el pueblo, cuya acción fuerza la coincidencia de los intereses minoritarios con los mayoritarios. Y el interés del pueblo español con relación a las colonias estaba claro: la independencia.

\section{BIBLIOGRAFIA}

AlBerich, J. (1980): «Actitudes inglesas ante el mundo hispánico en la época de Bello", Bello y Londres. Segundo Congreso del Bicentenario, Caracas, Fundación La Casa de Bello.

Atkinson, C. M. (1969): Jeremy Bentham. His Life and Work, Nueva York, Augustus M. Kelley.

Bent H AM, J. (1952): Economic Writings, W. Stark (ed.), Londres, George Allen \& Unwin.

- (1979): The Iberian Correspondence of Jeremy Bentham, P. Schwartz (ed.), Madrid. Londres.

Burns, J. H. (1966): «Bentham and the French Revolution», Transactions of the Royal Historical Society, vol. XVI, pp. 95-114.

Estelle, M. (1977): «Un Proyecto de Código para Chile», Revista Cbilena de Derecbo, vol. 4, pp. 359-363.

Everetr, C. W. (1966): Jeremy Bentham, Londres, Weidenfeld and Nicolson.

Halévy, E. (1901-1904): La Formation du Radicalisme Pbilosophique, París, Felix Alcan Editeur.

Hume, L. J. (1967): «Jeremy Bentham and the Nineteenth Century Revolution in Government», Historical Journal, vol. 10, núm. 4, pp. 361-375.

- (1970): "Jeremy Bentham on industrial management", Yorkshire Bulletin of Economic and Social Research, vol. 22, pp. 3.15.

- (1981): Bentham and Bureaucracy, Cambridge University Press.

Keeton, G. W., y SCh arzenberger, G. (1970): Jeremy Bentham and the Law, Westport, Connecticut, Greenwood Press.

LloRens, V. (1979): Liberales y Románticos, Valencia, Editorial Castalia.

POSNER, R. A. (1976): "Blackstone and Bentham", Journal of Law and Economics, vol. XIX, núm. 3, pp. 569-606.

RoBerTs, D. (1959): "Jeremy Bentham and the Victorian Administrative Statem, Victorian Studies, vol. 2, núm. 3, pp. 193.210.

Rodríguez Braun, C. (1984): Pensamiento Económico y Cuestión Colonial en el Siglo Clásico: Los casos de Bentham y Marx (tesis doctoral inédita), Madrid, Universidad Complutense.

SC H WARTZ, P. (1976): «La influencia de Jeremías Bentham en España», Información Comercial Española, núm. 517, pp. 37-57.

- (1983): «Cuatro Economistas ante el Fenómeno Colonial Español: Campomanes, Adam Smith, Flórez Estrada y Bentham", en ANes, G., y otros: Historia Económica y Pensamiento Social. Estudios en Homenaje a Diego Mateo del Peral, Madrid, AlianzaBanco de España.

Sch wartz, P., y Rodríguez Braun, C. (1983): "Cartas Españolas de Jeremías Bentham", Moneda y Crédito, núm. 165 , pp. 59.88 .

Stoetzer, O. C. (1966): El Pensamiento Politico en la América Española durante el Periodo de la Emancipación (1789-1825), Madrid, Instituto de Estudios Políticos.

Williford, M. (1980): Jeremy Bentham on Spanish America, Louisiana State University Press. 